\title{
Expression levels of CD47 on red blood cells during their storage in blood bank
}

\author{
KATARZYNA GMEREK ${ }^{1,2}$, ANNA STACHURSKA ${ }^{l}$, JADWIGA FABIJAŃSKA-MITEK ${ }^{1}$
}

${ }^{1}$ Department of Immunohaematology, Medical Centre of Postgraduate Education, Warsaw, Poland

${ }^{2}$ Regional Blood Donation and Therapy Centre, Warsaw, Poland

\begin{abstract}
Introduction: Red blood cells (RBCs) intended for transfusion can be stored under the blood bank conditions up to 42 days and prepared as leucodepleted (filtered) or non-leucodepleted units. During this time cells develop so-called "storage lesions" which can cause an adverse post-transfusion effect. It is suggested that senescent cell neoantigens appear among protein macrocomplexes: Rh, band 3 and glycophorin A (GPA) on the erythrocyte surface and initiate the binding of the natural autoantibody. CD47 is a transmembrane glycoprotein which is closely related to the Rh macrocomplex and is suspected to perform many roles in immunity, cell destruction and regulation of blood flow.

Aim of the study: To compare the CD47 expression on RBCs from "fresh" and "old" units with and without leucocytes.

Material and methods: The expression level of CD47 and percentage of labelled RBCs with antiCD47-PE were measured by the flow cytometer FACSCanto II (BD) using 50000 cells. For statistical analysis, Anova, $t$-Student and Kruskal-Wallis tests were used and $p<0.05$ was considered as significant.

Results: FC parameters have shown a statistically important fluorescence increase in "old" compared to "fresh" RBCs but the number of labelled RBCs in samples of "fresh" and leucodepleted units was larger than in other groups.

Conclusions: The expression of CD47 molecule changes during the RBCs storage and the presence of leucocytes in non-leucodepleted units significantly impacts its intensity.
\end{abstract}

Key words: CD47 role, senescence of red blood cells, storage of red blood cells.

(Centr Eur J Immunol 2013; 38 (2): 187-189)

\section{Introduction}

Red blood cells (RBCs) intended for transfusion can be stored under the blood bank conditions up to 42 days and be prepared as leucodepleted (filtered) or non-leucodepleted units. During this time cells develop so-called "storage lesions" $[1,2]$. An increased level of the glycolysis substrate 2,3-DPG and the energy storage ATP impair oxygen release, sodium potassium pump and RBC flexibility which is necessary for passage through small capillaries. After transfusion these adverse effects can be restored, but it takes hours or days. However, clinicians reported adverse transfusion effects of long-stored ("old") and non-leucodepleted RBCs on the recipient's recovery. Enhanced mortality and morbidity were observed especially in patients with the acute coronary syndrome, who are much more prone to hypoxia and thrombosis than others [3-5].

The process of RBC aging and phagocytosis by splenic macrophages is not exactly known yet. It is suggested that senescent cell neoantigens appear among proteins: $\mathrm{Rh}$, band 3 and glycophorin A (GPA) on the erythrocyte surface and initiate the binding of the natural autoantibody [1, 6-8]. CD47 is a transmembrane glycoprotein, named also integrin-associated protein, which is closely related to the Rh macrocomplex. Some of important roles of CD47 are suspected for example to be regulation of the migration, proliferation, survival of blood cells and some processes of innate and adaptive immunity. As a receptor of protein thrombospondin-1, it influences NO role in regulation of blood pressure, vascular flow and haemostasis [9-11]. The aim of this study is to

Correspondence: Associate Professor Jadwiga Fabijańska-Mitek, PhD, Department of Immunohaematology, Medical Centre of Postgraduate Education, Marymoncka 99/103, 01-813 Warsaw, tel. +48 2256938 20, fax +48 2256938 29, e-mail: immunohematologia@cmkp.edu.pl 


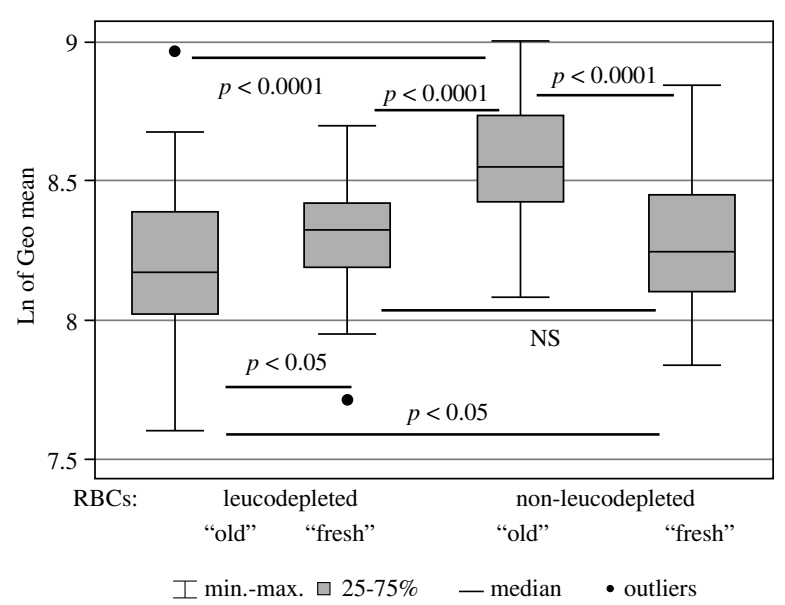

Fig. 1. Fluorescence intensity of CD47 in leucodepleted and non-leucodepleted RBCs during their storage ("old" vs. "fresh")

compare the CD47 expression on RBCs from "fresh" and "old" units with and without leucocytes.

\section{Material and methods}

Donations taken from 173 blood donors were processed to obtain leucodepleted (Atreus Whole Blood Processing System) or non-leucodepleted RBCs with an additive solution SAGM (saline, adenine, glucose, mannitol) in accordance with the standards currently applied in blood banks. Next, they were investigated as group I: 50 units of leucodepleted RBCs on $40^{\text {th }}-42^{\text {nd }}$ day of storage ("old"), group II: 40 units of leucodepleted RBCs on $2^{\text {nd }} 3^{\text {rd }}$ day of storage ("fresh"), group III: 43 units of non-leucodepleted "old" RBCs, group IV: 43 units of "fresh" non-leucodepleted RBCs. Distribution of Rh phenotypes was typical of our population: 29 (17\%) RhD negative and 144 (83\%) RhD positive, but it differed from $10 \%$ to $25 \%$ between groups. In a preliminary study, we excluded the impact of the D antigen on the expression of the CD47 molecule as well as its individual level in the donor. Therefore, tests were performed in unrelated groups. Samples were taken from tubes accompanying each blood unit and they were representative for each donation. RBCs were washed twice with PBS, and next labelled with PE-conjugated monoclonal antibody anti-CD47 (Becton Dickinson, USA). To exclude the autofluorescence, unlabelled cells as a negative control were incubated in PBS under the same conditions $\left(30 \mathrm{~min}\right.$ at $37^{\circ} \mathrm{C}$ in a dark chamber) as the labelled ones. Both unlabelled and labelled samples were washed and suspended in PBS buffer supplemented with $0.1 \%$ BSA. The expression level of CD47 and percentage of labelled RBCs were immediately measured by flow cytometer FACSCanto II (BD) using 50000 cells. Cytometer setup and calibration was performed using the Cytometer Setup and Tracking (CST) beads and CST Mod-

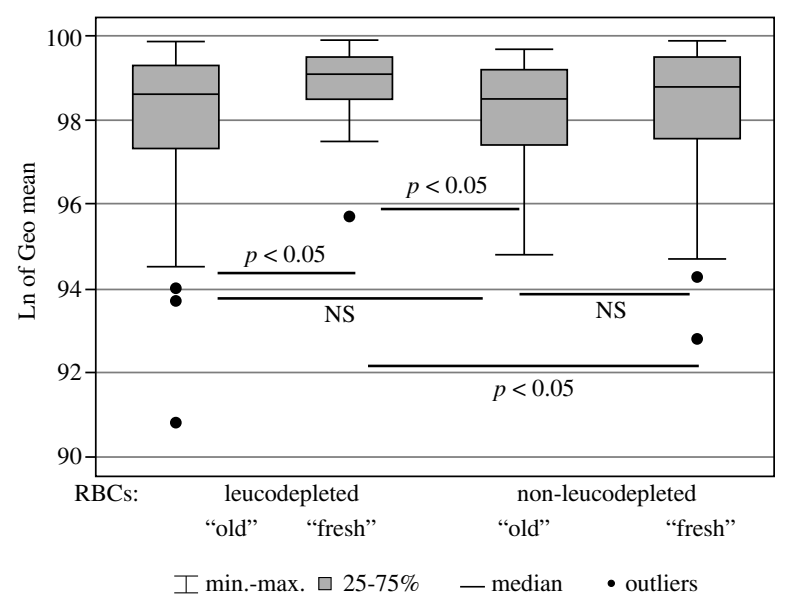

Fig. 2. Percentage of labelled RBCs with anti CD47-PE in tested samples of each group

ule, according to the manufacturer's recommendation. This system enables setting optimal voltages of photomultipliers for used detectors, including phycoerythrin detector. The antibody titration curve allowed us to choose optimal Ig concentration over which fluorescence intensity value demonstrated a constant level. Results of geometric mean fluorescence values were calculated using computer software (Excel, Microsoft; STATA 2012). For statistical analysis, Anova and $t$-Student test were used for parameters with normal distribution and Kruskal-Wallis test for others. $P$ values of less than 0.05 were considered as significant.

\section{Results}

FC parameters have shown a statistically important fluorescence increase in "old" non-leucodepleted RBCs compared to "fresh" leucodepleted and non-leucodepleted RBCs $(p<0.0001)$. The fluorescence value of "old" leucodepleted RBCs is also statistically larger than that of "fresh" ones, but the difference was smaller than in samples from non-filtered units $(p<0.05)$ (Fig. 1). "Fresh" leucodepleted RBCs were the most homogeneous population taking into account the number of labelled cells in relation to "old" non-leucodepleted $(p<0.005)$ and leucodepleted $(p<0.05)$ RBCs (Fig. 2).

\section{Discussion}

The CD47 molecule expression and its role on RBCs aging were studied mainly on mouse models. For example, "young" and "old" cells were isolated from the circulation, due to their density and it was found that the expression of CD47 is 30\% lower in "old" than in "young" ones [12]. Authors considered that the loss of CD47 can lead to the removal of cells from the circulation because CD47-deficient mice showed accelerated clearance of erythrocytes 
comparing to wild-type (WT) mice. Also, CD47-deficient RBCs transfused to WT mice had a shortened life span, which was interpreted as a lack of ability to inhibit macrophage activation and phagocytosis $[6,13]$.

Other studies have shown that knock-out CD47-/- mice developed autoimmune haemolytic anaemia (AIHA) [14, 15], but in studies of AIHA patients there was no decrease in CD47 expression [3]. On the other hand, a decreased $\mathrm{CD} 47$ expression was noted in patients with $\mathrm{Rh}_{\text {null }}$ phenotype, but they also had a reduced level of other components of the membrane macrocomplex: Rh, band 3, GPA and some of blood group antigens. In humans, the $\mathrm{Rh}_{\text {null }} \mathrm{RBCs}$ have shorter survival, but it is not known whether CD47 deficiency is just responsible.

Some authors showed that CD47-SIRP $\alpha$ (Signal-regulatory protein) binding interactions are different between mice and humans and their significance in humans is less clear. Probably it is caused by phylogenetic divergence and species specificity at a biochemical and genetic level $[9,13$, 16]. Also, one should not compare the RBC senescence in vivo and in vitro [16]. Some authors observed the decrease in CD47 expression on erythrocytes during storage, but pointed out that the results may depend on the methodology of blood samples preparation $[1,17]$. Others showed an increased expression of various antigens during aging of mouse erythrocytes [18]. It may be comparable with our serological testing of human autoantibodies and their strong reactivity with "old" RBCs [19]. It has also been shown that the expression of CD47 is enhanced on haematopoietic cells stored with leucocytes and it can be an important mechanism that provides protection against phagocytosis [20]. A phenomenon like that can also play a role in long-stored units of non-leukoreduced RBCs presented now. During storage, residual leucocytes release cytokines, enzymes and other bioreactive molecules which can alter the RBC membrane and increase RBC adherence to endothelial cells [21, 22].

Because the expression of CD47 molecule changed during the RBCs storage and the presence of leucocytes in nonleucodepleted units significantly impacts its intensity, further studies of its importance to the quality of the transfused blood will be continued.

\section{The authors declare no conflict of interest.}

This study was supported by 502-1-26-01-12 CMKP grant and was performed with official consent of the Research Bioethics Committee.

\section{References}

1. Sparrow RL, Healey G, Patton KA, et al. (2006): Red blood cell age determines the impact of storage and leukocyte burden on cell adhesion molecules, glycophorin A and the release of annexin V. Transfus Apher Sci 34: 15-23.

2. van de Watering L (2011): Red cell storage and prognosis. Transfusion 100: 36-45.
3. Rao SV, Jollis JG, Harrington RA, et al. (2004): Relationship of blood transfusion and clinical outcomes in patients with acute coronary syndromes. JAMA 292: 1555-1562.

4. Al-Sarraf A, Fowler RA (2005): Is blood transfusion harmful in patients with acute coronary syndromes? JAMC 172: 182.

5. Weinberg JA, McGwin Jr G, Griffin LG, et al. (2008): Age of transfused blood: an independent predictor of mortality despite universal leukoreduction. J Trauma 65: 279-284.

6. Garratty G (2008): The James Blundell Award Lecture 2007: Do we really understand immune red cell destruction? Transfus Med 18: 321-334.

7. Kay MMB (1992): Senescent cell antigen and band 3 in aging and disease. Prog Cell Res 2: 245-250.

8. Petz LD, Garratty G: Specificities not associated with blood group antigens. In: Immune Hemolytic Anemias. Second edition. Elsevier Inc. 2004, 243-245.

9. Barros MMO, Yamamoto M, Figueiredo MS, et al. (2009): Expression levels of CD47, CD35, CD55, and CD59 on red blood cells and signal-regulatory protein- $\alpha, \beta$ on monocytes from patients with warm autoimmune hemolytic anemia. Transfusion 49: 154-160.

10. Lindberg FP, Lublin DM, Telen MJ, et al. (1994): Rh-related antigen CD47 is the signal-transducer integrin-associated protein. J Biol Chem 269: 1567-1570.

11. Isenberg JS, Roberts DD, Frazier WA (2008): CD 47. A new target in cardiovascular therapy. Arterioscler Thromb Vasc Biol 28: 615-621.

12. Khandelwal S, van Rooijen N, Saxena RJ (2007): Reduced expression of CD47 during murine red blood cell (RBC) senescence and its role in RBC clearance from the circulation. Transfusion 47: 1725-1732.

13. Sekigami-T, Kaneko Y, Saito Y, et al. (2006): Enhanced phagocytosis of CD47-deficient red blood cells by splenic macrophages requires SHPS-1. Biochem Biophys Res Com 343: 1197-1200.

14. Oldenborg P-A, Zheleznyak A, Fang Y-F, et al. (2000): Role of CD47 as a marker of self on red blood cells. Science 288: 2051-2054.

15. Oldenborg P-A, Gresham HD, Lindberg P (2001): CD47-signal regulatory protein $\alpha(\operatorname{SIRP} \alpha)$ regulates $\mathrm{FC} \gamma$ and complement receptor-mediated phagocytosis. J Exp Med 193:855-861.

16. Sparrow R, Healey G (2006): Reduced expression of CD47 on stored red blood cells. Transfusion 46: 1263.

17. Luk CS, Gray-Statchuk LA, Cepinkas G, et al. (2003): WBC reduction reduces storage-associated $\mathrm{RBC}$ adhesion to human vascular endothelial cells under conditions of continuous flow in vitro. Transfusion 43: 151-156.

18. Subramaniam S, Boder ET, Discher DE (2007): Phylogenetic divergence of CD47 interactions with human signal regulatory protein $\alpha$ reveals locus of species specificity. J Biol Chem 282: $1805-1818$.

19. Gmerek K, Fabijańska-Mitek J, Łoniewska-Lwowska A (2012): Impact of red blood cell storage under the blood bank conditions on their reactivity with autoantibodies. Centr Eur J Immunol 37: 243-246.

20. Jaiswal S, Jamiesion CHM, Pang WW, et al. (2009): CD47 is upregulated on circulating hematopoietic stem cells and leukemia to avoid phagocytosis. Cell 138: 271-285.

21. Khandelwal S, Saxena RK (2007): Age-dependent increase in green autofluorescence of blood erythrocytes. J Biosci 32: 11391145.

22. Sparrow RL, Veale MF, Healey G, et al. (2007): Red blood cell (RBC) age at collection and storage influences RBC membrane-associated carbohydrates and lectin binding. Transfusion 47: 966-968. 